\title{
Dictionary Quality and Dictionary Design: A Methodology for Improving the Functional Quality of Dictionaries
}

Piet Swanepoel, Department of Afrikaans, University of South Africa, Pretoria, Republic of South Africa (swaneph@alpha.unisa.ac.za)

\begin{abstract}
Although recent dictionaries for the ESL market have been praised for their innovative design features, the prime concern of users, lexicographers and metalexicographers is the functional quality of the dictionary products provided for the market. The functional quality of dictionaries and the scientific assessment thereof forms the topic of this paper. The functional quality of dictionaries is defined in section 2. In section 3 the current methodological approach to assessing the functional quality of texts in the fields of web design, instructional design and document design is discussed and its relevance for dictionary design is indicated. Section 4 explicates in more detail how this methodology can be used to design functional dictionaries and to assess the functional quality of the design features of existing dictionaries.
\end{abstract}

Keywords: FUNCTIONAL QUALITY, DICTIONARY DESIGN, WEB DESIGN, INSTRUCTIONAL DESIGN, DOCUMENT DESIGN, RESEARCH METHODS, THEORETICALLY MOTIVATED EMPIRICAL RESEARCH

Opsomming: Woordeboekkwaliteit en woordeboekontwerp: 'n Metodologie vir die verbetering van die funksionele kwaliteit van woordeboeke. Alhoewel die jongste woordeboeke vir die Engelse aanleerdersmark geprys word vir hulle vernuwende ontwerpkenmerke, is die hoofbelang van gebruikers, leksikograwe en metaleksikograwe die funksionele kwaliteit van die woordeboeke op die mark. Die funksionele kwaliteit van woordeboeke en hoe dit wetenskaplik bepaal kan word, is die hooftema van hierdie artikel. In afdeling 2 word die funksionele kwaliteit van 'n woordeboek nader omskryf. Afdeling 3 gee 'n uiteensetting van die metodologie wat op die gebied van webgebaseerde onderrig en teksontwerp gevolg word om die funksionele kwaliteit van tekste te bepaal en die relevansie daarvan vir woordeboekontwerp word aangedui. Die gebruik van hierdie metodologie vir die ontwerp van funksionele woordeboeke en vir die vasstelling van die funksionele kwaliteit van die ontwerpkenmerke van bestaande woordeboeke word in afdeling 4 bespreek.

Sleutelwoorde: FUNKSIONELE KWALITEIT, WOORDEBOEKONTWERP, WEBONTWERP, INSTRUKSIONELE ONTWERP, TEKSONTWERP, NAVORSINGSMETODES, TEORETIES-GEMOTIVEERDE EMPIRIESE NAVORSING

\section{Introduction: The Problem of Dictionary Quality}

English lexicographers have responded to the mounting international demand for English by providing the market with a wide range of lexicographic works 
to assist in the use and acquisition of English as a second or a foreign language (ESL/FL). This makes the ESL/FL lexicographic market one of the most competitive dictionary markets in the world, and one in which, as Herbst (1999) notes, publishing houses are continually under pressure to come up with innovative products to keep an edge on their competitors and to protect their share of the lexicographic market.

The existing English monolingual advanced learner's dictionaries (MLDs) are a case in point. No less than four of them compete in the market, viz. CIDE, COBUILD2, LDOCE3 and OALD6. All four of them are intended as multifunctional lexicographic tools to assist as wide as possible a target group in whatever SL communicative and learning activities they engage. They have been labelled the "big four", and praised by a number of reviewers as the pinnacle of monolingual learner lexicography, especially so, on grounds of their innovative (re)design features.

The big four MLDs have been praised, but then with a number of provisos, for the innovative way in which the problems of learners have been approached by redesigning various aspects of the content, structure, style, etc. of these dictionaries (cf. Herbst 1999, Rundell 1999 and Scholfield 1999). The three most common problems learners experience when using these dictionaries are:

- finding the relevant information,

- having found it, comprehending it,

- applying what has been comprehended to the specific lexical problem that triggered the dictionary look-up

(cf. Bogaards 1998, Scholfield 1982).

The findability problem within dictionary entries is addressed, for example, by basing the ordering of senses on corpus frequency data and the use of so-called "signposts" and/or advance-organizers.

The comprehension problem, on the other hand, is addressed by a number of innovative design features, some of course, older than others, e.g.

- the use of a controlled/limited defining vocabulary in definitions,

- the elimination of all kinds of dictionarese (symbols, labels, some abbreviations, parentheses, etc.) and arcane expressions in definitions and incorporating some of the information traditionally conveyed by these means in the dictionary definitions themselves,

- the use of a full sentence definition format that imitates the style and structure of "folk definitions" of native speakers (cf. especially COBUILD),

- the use of corpus-driven contextual paraphrases as a defining technique to help learners match generic abstract definitions with the specific senses of target words in their contexts of use, 
- the use of definitional schemata to ensure comprehensiveness and systematicity in defining the meaning of headwords that belong to the same grammatical and/or semantic class,

- extended information on the paradigmatic sense relations of target words (hyponyms, synonyms, and antonyms),

- the extended use of authentic example sentences to illustrate a target word's collocational features, selectional restrictions and stylistic characteristics in addition to its meaning-in-use,

- the use of extensive (nonverbal) illustrations to support definitions and to clarify a wide range of the semantic features of target words, and

- the use of extended usage notes to elucidate the meaning and use of target words, and especially to disambiguate semantically related words.

Although innovativeness might be a crucial commercial concern, dictionary users, including teachers of English, place a higher premium on the functional quality of the dictionaries they eventually purchase, i.e., on the degree to which a dictionary successfully provides them with the kind of lexical support they need for the various kinds of SL communicative and learning activities in which they engage.

When they state that "lexicography as practice and the theory of lexicography have a common goal, namely to foster the effective use of dictionaries" (Hausmann, Reichmann, Wiegand and Zgusta 1989: XVII), the editors of the comprehensive International Encyclopaedia of Lexicography underline the fact that the functional quality of dictionaries should be one of the main issues with which we concern ourselves.

A crucial question for learners, teachers, lexicographers, and metalexicographers alike, should then be:

- How functionally effective are the available ESL/FL English dictionaries in providing learners with the kind of lexical support they need in the various receptive, productive and learning activities in which they engage?

For lexicographers and metalexicographers a second crucial question is:

- If not functionally effective, what kind of dictionaries, both with regard to dictionary type and qua their design (i.e. with regard to content, structure, style, presentation and integration in instructional activities and materials, etc.), would optimize lexical support for different kinds of users' needs in different contexts of use and acquisition?

In Swanepoel (2000), I argue and demonstrate that, despite the commitment to improving the functional quality of dictionaries, practical lexicography and metalexicographic research are currently troubled by two major methodological problems, viz. that 
- the evaluation of the functional quality of dictionaries does not feature prominently in either the dictionary design process, nor in current metalexicographic research, and

- when it does feature, it is most often based on impressionistic and anecdotal evidence or common-sense heuristics, not on the application of generally accepted scientific methodologies and techniques, such as theoretically driven experimental research.

The crucial point is that the introduction of all kinds of innovative features in monolingual learner's dictionaries does not in itself guarantee an improvement of their functional quality. The functionality of each of these innovative features has to be tested empirically as there is simply no mechanical transfer of the content of dictionaries to the mental lexicon of the learner/user. Any dictionary consultation constitutes a complex cognitive process in which a number of crucial mediating variables determine the success with which various kinds of learners/users infer, process, acquire and use information from dictionaries of various types and designs in different contexts of use.

The second important point is the fact that lexicographic and pedagogic experience or "informed opinion" can guide hypothesis formation in theory construction and empirical testing, but on its own it is not enough to elucidate the real problems learners experience with the functionality of dictionaries. For one, these assumptions may simply be wrong, misguided, or have little empirical support beyond the limits of the lexicographer's, teacher's or even dictionary reviewer's own subjective experience (cf. Sims-Knight 1992).

A telling example of this is the empirical experiment reported on in Cumming, Crop and Sussex (1994) in which the authors question the commonly held belief that the full-sentence definition format (cf. the list above) is superior to the phrasal definition format. The full sentence definition is an innovative feature introduced into modern learners' lexicography by COBUILD, and has now become a standard feature of a number of MLDs. What these authors then demonstrate in their research is that production and performance measures do not in fact vary over the use of the phrasal definition format and the sentence definition format.

Despite the apathy towards questions concerning the real functional quality of dictionaries, the need to address the questions posed above and for appropriate methodologies and techniques to answer them, has not diminished. In fact, it has required a renewed urgency with the advent of electronic dictionaries. As Nesi (2000) points out in her overview of the development of electronic dictionaries, the obsession with the technical possibilities of the new media has given way to a concern with how these technical possibilities can, via the design of such dictionaries, best support the needs and capabilities of the end-user (cf. also Køhler Simonsen 2000, Laufer 2000, Müller-Landmann 2000, Sato 2000 and Tono 2000).

Nesi (2000: 846) concludes: 
Electronic dictionaries are certainly capable of offering the user choices of source material, search routes, and level of detail ..., yet we still know little of the benefits of different potential options. An exciting new medium demands creative new approaches to dictionary design, and more thorough exploration of dictionary users' wants and needs.

Given the priority the functional quality of dictionaries should have in the field of lexicography, the main aim of this article is

- to explicate how the functional quality problem is approached in three closely related fields, viz. that of document design, web design and instructional design, and

- to indicate the relevance and applicability of the methodologies and techniques of these fields not only for tackling the functional quality problem in the field of (E)SL lexicography, but also for various other kinds of dictionaries.

In section 2, I focus on the problem of defining the notion of "functional quality" with regard to dictionaries, i.e. what has to be measured. In section 3, the current methodological approach to assessing the functional quality of texts in the fields of web design, instructional design and document design are discussed and its relevance for dictionary design are indicated. Section 4 explicates in more detail how this methodology can be used to design functional dictionaries and to assess the functional quality of the design features of existing dictionaries.

It must be stressed though, as pointed out in Swanepoel (2000), that the apathy in the field of lexicography towards empirical research on the real functional quality of dictionaries, does not imply that no relevant research has been done on the topic. As will be indicated in the rest of this article, various researchers in the field have addressed questions relating to the functional quality of dictionaries. The methodological framework outlined in the rest of this article provides a coherent framework within which such contributions can be evaluated and integrated into a coherent methodological programme.

\section{2. $\quad$ Defining "Functional Quality"}

\subsection{Exploring the Concept of "Dictionary Effectivity"}

As indicated in section 1, it is generally accepted that practical lexicography and metalexicography have a common goal, namely to foster the effective use of dictionaries.

However, when it comes to the use of dictionaries, "effectivity" or "efficacy" is a slippery concept, desperately in need of clarification if it is to serve as basis for the design of effective dictionaries. 
The editors of An International Encyclopaedia of Lexicography fail to define or explicate what they mean by "effectivity", or to provide answers to the such important questions as, for example,

- whether effectivity is a monolithic or complex construct and what its defining parameters would be,

whether effectivity is a function of the dictionary user, the dictionary itself, or both, or even of a larger number of variables under which the dictionary and the user are included,

- how effectivity translates to concrete design principles for various kinds of dictionaries, for different target users, in different contexts of use, and

- how effectivity should be operationalized and measured.

However, if we pretheoretically define the effectivity of a dictionary as the degree or measure in which a dictionary supports its users in accomplishing certain communicative and learning activities, then it should be obvious that various lexicographers and metalexicographers have touched on the topic. A survey of the literature reveals that it is discussed under various labels and in various guises, as for example, in research on dictionary use (user research: who uses what kind of dictionary in what contexts of use and with what effect). It also features prominently in dictionary reviews and the study of dictionary criticism, and in articles that suggest innovative ways for the improvement of the design of dictionaries. Research that highlights the kinds of problems users experience with monolingual learner's dictionaries (e.g., the findability, comprehensibility and applicability problems referred to by Bogaards (1998)) have direct bearing on the kinds of variables that determine the effective use of dictionaries.

Furthermore, improving the effectivity of the dictionary lies at the heart of the various principles or heuristics for the design and compilation of effective dictionaries expounded in the literature, especially handbooks on practical lexicography. What one misses, however, is an assessment of the validity of these principles, i.e. whether they have been proven empirically to improve the functional quality of dictionaries.

Secondly, from a survey of the literature it should also be obvious that effectivity itself is a complex concept, and that the effectivity of a dictionary is a function of a number of variables. These would include, for example, a number of

user variables, such as users' referential skills, their ability to detect and determine their lexical needs in specific communicative situations, their linguistic competency, their ability to infer and process information provided in dictionaries and their ability to apply this knowledge in various communicative and learning tasks, their learning and cognitive styles and their preferences for certain dictionaries when experiencing gaps in 
their lexical knowledge,

- dictionary variables, of which the design elements of dictionaries are amongst the most prominent, i.e. their content, structure, style, layout, and medium (e.g. printed vs. electronic dictionaries),

- functional and contextual variables, i.e. the different kinds of functions for which dictionaries are used (e.g. encoding, decoding, translating and learning functions) in different contexts of use (in the classroom, using a CALL application, i.e. electronic format), and

- external limitations, i.e. variables that are imposed on the design of dictionaries (e.g. constraints of space, developmental cost, person power).

There may, of course, be a number of other variables not subsumed under those mentioned above. What determines the effectivity of a dictionary is, after all, an empirical question - one that has to be explored through systematic research with the aid of existing research methodologies and techniques. To this end, we are in a dire need of some coherent framework in which all these variables can be subsumed and systematically organised, and their content, effectivity measures (e.g. relevance, efficiency, clarity, accessibility, etc) and their internal relationships (e.g. correlational or causal) can be explored.

What we need, more specifically, is research within this framework, that can provide lexicographers with some very concrete answers to such questions as the following:

- What kind of content should a dictionary have to adequately support the lexical needs of a user for a specific task?

- How does one organize/structure this content (both at the macro- and microstructural level) to optimize its accessibility for various kinds of users?

- To what kind of stylistic criteria should the presentation of dictionary content adhere in order to optimize comprehensibility?

- How does one have to adapt the content, structure, style and layout of a dictionary if it is provided as part of a CALL application to optimize its use in various kinds of decoding, encoding and SL learning activities?

\subsection{Redefining "Dictionary Effectivity"}

In section 1 of this article, I subsumed the concept of dictionary effectivity under the concept of the functional quality of a dictionary. This concept I defined for heuristic purposes as the degree to which a dictionary successfully provides dictionary users with the kind of lexical support they need for the various kinds of SL communicative and learning activities in which they engage. In the light of the numerous variables discussed above that have an impact on the effectivity of a dictionary we can refine this definition to the following: 
The functional quality of a dictionary is the degree to which a dictionary, qua its design features (i.e. its content, structure, style, layout, and medium), within the limits of its intended function(s), and the competencies of its (target) users, successfully provides them with the kind of lexical support they need for the various kinds of SL communicative and learning activities in which they engage in different contexts of use.

This definition aims at providing a framework against which a number of the variables that bear on the effective use of dictionaries can be explicated.

As stated, it is a definition that has been narrowed down to the functional qualities of dictionaries. The concept of "functional quality" is borrowed from research on the communicative quality of document design (cf. Van Waes, Woudstra and Van den Hoven 1994) where it forms part of three explicit criteria - also applicable to the evaluation of dictionaries - on which readers/users assess the quality of a document, viz.

- its functional quality, as defined above (i.e. the quality of help it provides for specific tasks, goals or functions),

- its technical quality (quality of technical features, such as binding, size, portability, etc.), and

- $\quad$ its aesthetic quality (aesthetically pleasing appearance) (cf. Shelby 1994).

Although I will not pursue the nature of the other two criteria/heuristics here, they will also have to feature in more comprehensive and systematic empirical research on the range of variables on which users base their decisions on the quality of a dictionary.

\section{Mapping and Measuring Functional Quality}

Having determined what constitutes the functional quality of a dictionary, one has to deal with the question of how to go about designing a dictionary that is optimally functional with regard to its intended functions, target users and different contexts of use.

In this section, I will give an overview of how this question with regard to different kinds of documents or texts is approached in three other related fields, viz. document design, web design and instructional design. These three fields share a common generic set of methodological assumptions, models, procedures and techniques, but with specific adaptations according to the end product (documents, web sites, instructional materials) and the processes involved in designing and developing the end product.

In all three these fields the problem of optimizing the functional quality of the end product is approached from two closely related perspectives:

- the process that should be followed in designing the product, and 
- the design features the end-product has to possess to ensure its optimal usability/functional quality.

\subsection{The Design Process}

In all three these fields adaptations of the so-called ADDIE model (Analyse Design - Develop - Implement - Evaluate) (cf. figure 1) is followed in the design process (cf., e.g., Gaffney 2000, Multimedia Services 2000, Nielsen 1994, 1999, Schellens and Steehouder 1994 , Wilson, Jonassen and Cole 1993).

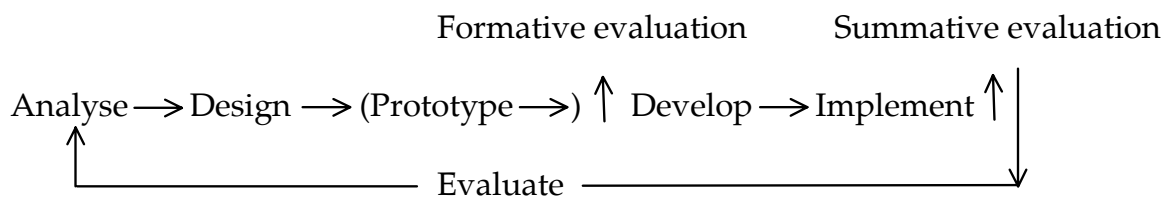

Figure 1: The ADDIE model

Underlying this model is the assumption that the optimal design of an endproduct should be approached according to a problem-solving strategy. The model specifies a number of, often overlapping, and cyclic steps that should be followed in the design process to ensure the best design. The main activities and the kind of result of each, can be described as follows:

- Analyse: Determine and analyse all the variables that have been proven (experimentally) to mediate the successful use/functional quality of the document. (Cf. the discussion below.)

Outcome: An analysis report, indicating, for example, the existing need for a document (needs analysis), usage trends, features of competing products, etc.

- Design: Design an outline for the product, i.e. make specific choices with regard to genre, content, structure, style, layout, format and delivery medium, as dictated/motivated by the relevant variables analysed in the analysis phase/plan.

Outcome: Usually a project plan with a style guide in which each of the design elements of the document are specified. Very often this includes a prototype of the document, with detailed descriptions of subsections of the document. In a detailed project plan there are also often specifications with regard to production processes to be followed, specification of sources to be used and, especially in the case of collaborative writing projects, a specification as to who will be responsible for what tasks.

- Develop: During this phase a first/concept draft of the final document is produced according to the specifications of the project plan and style guide, and the final draft after editing.

Outcome: The final document. 
- Implement: In the case of a web design and instructional design this refers to the phase in which the product is released for use by the target users in (specified) contexts.

- Evaluation: Although evaluation is stipulated in most versions of the model as a phase that follows on implementation, it forms the cornerstone of all activities/phases in the model specified in figure 1.

Before elaborating on the various phases involved in the design process, the focus will first of all be on the process as a whole and especially on the role of evaluation within the process.

\subsubsection{Evaluating Design}

According to system theory from which this model originates, any design process requires constant monitoring. Evaluation has to act like a thermostat, always monitoring the system's effectiveness and pointing out what revisions are needed to adapt the system to differences in different contexts of use (Wilson, Jonassen and Cole 1993). Design and evaluation, therefore, go hand in hand.

Specific formative and summative evaluation checks are specified for the design process. Formative evaluation involves quality control of the product in the stage before (mass) production, i.e. in a stage in which adjustments can still be made to a draft, prototype or concept text. Summative evaluation, on the other hand, involves control of the functional quality of a product after (mass) production within its intended contexts of use with its intended users. Results of both these quality checks are fed back into the design process: formative evaluation to the improvement of a concept text, summative evaluation into the redesign of an existing text.

Rapid prototyping is itself a specific form of quality control. Given the high cost of extensive analysis and project planning, a small-scale prototype is constructed that exhibits all the key features of the intended end-product. The prototype is tested (with its intended users) in an effort to get a clearer picture of the requirements to which the end-product will have to adhere. The revised prototype is then used as a model for the construction or development of the final product.

Within the three fields under scrutiny, a number of instruments have been developed to test the functional quality of a text before final production. Of these, expert- and user-orientated methods seem to dominate. In the case of expert-evaluation design experts are asked to determine whether a prototype or end-product adheres, in their opinion, to its intended functions and the needs of the target users. In web design, for example, this form of evaluation known as "heuristic evaluation" - has become one of the most popular formative evaluation procedures (cf. Nielsen 1994, 1999 and De Jong and Van der Geest 2000). The evaluation itself, proceeds on the basis of how well a design adheres to a set of recognized usability principles (cf. Van der Geest and Spyri- 
dakis 2000, and De Jong and Van der Geest 2000 for an overview).

Expert-evaluation has much in common with the text-based approach developed in the field of document design. A number of well-motivated checklists and models have been developed to improve the functional quality of specific text types. As in the case of the heuristics that are suggested to improve interface and web design, these checklists are often meant to serve a double purpose: either as guidelines to be followed in the design of a product, or as instruments to evaluate an existing product.

In the case of user-orientated methods, a sample of the intended target group itself is selected and their response to the functional quality of a text is elicited and evaluated. The main aim again is to pinpoint all the problems users experience with a text, given its intended functions, the users' information needs and their competencies. Think-aloud protocols have proven to be valuable instruments for this purpose. The user-orientated approach dominates in the field of instructional design and the full set of empirical research methods are used, including the tools and techniques offered by CALL applications, such as tracking technology (cf. Lomicka 1998, and Schriver 1989, 1993 for an overview of the user-approaches in document design).

Some researchers have tried to determine which of these methods provide the designer with the best kind of feed-back for improving the design of a product. Although user-evaluation is often given priority, it is well-established that expert evaluation is an adequate instrument to detect the most, and most severe, problems of a text. However, given the fact that the two methods often focus on different kinds of problems with the functional quality of a text, a combination of the two methods more than often gives the best results.

\subsubsection{Process Approaches in Dictionary Design}

What processes are followed in dictionary (re)design?

Given the high costs involved in publishing commercial dictionaries and given the complexity of the task of coordinating the various processes in producing and publishing a dictionary, one could safely assume that publishing houses do some form of planning for the production of a dictionary, and that they go at least through some of the stages referred to in the ADDIE model. However, given the current state of research, it is not at all sure what of these stages are involved, and, especially, if and what form(s) of assessment of the functional quality of the dictionaries are involved. Given the competition in the field, publishing houses are rather discreet about their trade secrets and very few of the (in-house) documents that are generated in the design process reach the public arena.

Although some publishing houses claim in their sales materials that some form of research underlies the design of their dictionaries, they seldom elaborate on what kinds of research were conducted, what theoretical assumptions and methodologies were involved, or on how the results of such research were fed into the design process. In short, we have very little knowledge of how lexi- 
cographers themselves go about the design process and how the process approach is utilized to enhance the functional quality of dictionaries. In this regard the ADDIE model provides a framework to guide such research and for synthesizing existing lexicographic approaches and practices as discussed below.

Within the field of lexicography, proof of the effectiveness of the process approach to dictionary design is provided in De Schryver and Prinsloo (2000). The authors outline a procedure for enhancing the functional quality of a dictionary by eliciting feedback from users on crucial design issues during the various stages in the production of a dictionary.

However, there does not yet exist a comprehensive set of heuristics for either the formative or summative evaluation of dictionaries. The evaluation of dictionaries is, however, the prime concern of dictionary criticism - a clearly demarcated field of research within the field of lexicography. What needs to be done, is

- a systematic description and assessment of the criteria or heuristics that dictionary critics themselves employ in evaluating dictionaries, and

- a description and assessment of the functional quality of the design features that are incorporated into dictionaries of various kinds.

(Cf. Swanepoel 2000 for a discussion of how these issues are currently dealt with in dictionary criticism and in research on the content and structure of dictionaries as texts.)

A general outline of how such evaluation/design criteria and specific design proposals for improving the functional quality of dictionaries can be systematically described and evaluated is provided by the template proposed in De Jong and Van der Geest (2000) for the description and evaluation of web heuristics.

\subsection{Analysis}

According to the ADDIE model, the first two steps in the design process consists of analysis and then of design informed by the results of the analysis.

The main aim of the analysis stage is to determine and analyse all the variables that have been proven experimentally to have an impact on the functional quality of a document. Given this input, a document is then designed with regard to the choice of its content, structure, style, layout and medium in a way that will optimize its functional quality within the range of requirements set by the mediating variables that impact on its functional quality.

In the field of document design, for example, four crucial variables have been identified that have a direct impact on the functional quality of a document - variables that, therefore, crucially determine the design features of a functional document (cf. figure 2), viz.

- the intended function(s) of a document (What is the document going to 
be used for?),

- the target users (Who is going to use the document?),

- the context of use (In/under what circumstances will the document be used?), and

- the marginal restrictions on the design of the document (What restrictions of time, financial and human resources apply?).

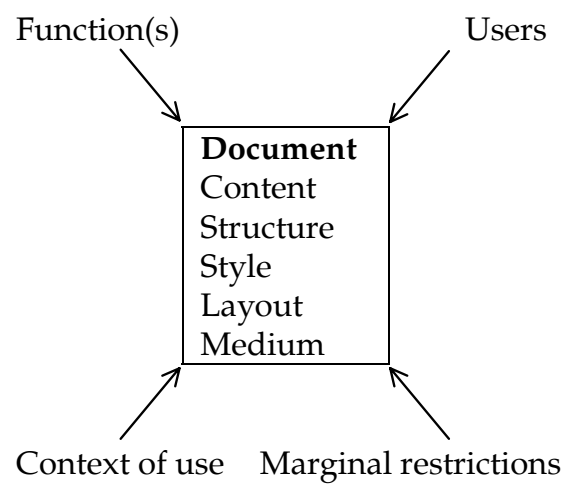

Figure 2: Variables that determine a document's design

In the literature of document design, attention is given to the way in which each of these variables correlate with/determine the functional quality of a document qua its design elements, and to the most appropriate methods to analyse each of these variables (cf., e.g., Hoeken 1995).

\subsubsection{Lexicographic Approaches}

Although not always explicitly stated as such, much of the descriptive research done within in the field of lexicography in fact also falls within the parameters defined in figure 2. For example:

- User research focusses on the question of who (users) use what kind of dictionary (document) for what purpose (functions) under what conditions of use (context of use). Wiegand (1998) has recently developed a fully fledged, theoretically motivated framework for precisely analysing these variables (users, functions, contexts of use).

- Dictionary criticism, as a form of expert evaluation, focusses on the problems that various kinds of users do or could in principle experience with specific design elements of particular dictionaries.

- Research on the structural elements of dictionaries aims at providing a comprehensive taxonomic description of the design elements of dictionaries which can provide lexicographers with various design options to explore in an effort to optimize the functional quality of a dictionary. 
What is crucially missing from dictionary research, however, is that there is hardly any systematic effort to determine experimentally how each of the variables listed above (user, functional, usage variables) in fact impact on the design of a functionally effective dictionary and, thus, what requirements they set for designing a dictionary of a specific kind (cf. Swanepoel 2000). The result is that much of these research results can only be used as basis for preliminary hypotheses about the design of a functional dictionary of a specific kind. As indicated in the ADDIE model, such designs of necessity have to be experimentally assessed by way of formative and summative techniques. What is needed, therefore, is experimental research to determine how each of the variables listed above, separately and in conjunction with each other, determine the functional quality of each of the design elements of a dictionary.

\subsection{Functional-cognitive Design}

In all fields under consideration, it is accepted that user variables have a crucial role to play in the design of a document/dictionary (cf. also the discussion in section 2). In cognitive approaches to document design, it is assumed more specifically that the functionality of a document is crucially determined by the degree to which it supports - qua its design elements - the cognitive processes and representations required of users to successfully consult a document for a specific purpose (function). (Cf., e.g., Hoeken 1995 for a discussion of how cognitive factors impact on the design of documents.)

Given the importance of this approach to the design of effective lexical support in SL instructional design (cf. Groot 2000, Hegelheimer and Chapelle 2000, Plass 1998, and Swanepoel and Van de Poel 2000), the functional-cognitive approach to document design is explicated in more detail below.

In the functional-cognitive approach the design of a document starts off with an analysis of the cognitive processes and representations required for the successful completion of a specific decoding, encoding or acquisition task (e.g. reading or writing in a SL or acquiring the vocabulary of a SL). The second step is to determine how each of the design elements of a document could support this process. To this end, designers rely on what is available by way of empirically supported theories of information processing, and, more specifically, by way of theories of SL processing in different contexts of use. These theories provide the rational basis for the design of a document in as much as the design of the document (i.e. its content, structure, style and layout) is determined by the cognitive processes and representations involved.

Given the hypothetical nature of these processing theories, the design phase is always followed by empirical evaluation of the functionality of such a document by evaluating the success with which the user is able to complete a specific task with the aid of the document under consideration. The results of the evaluation of the functional quality of the document is then fed back into the (re)design process. This approach is presented schematically in figure 3 : 


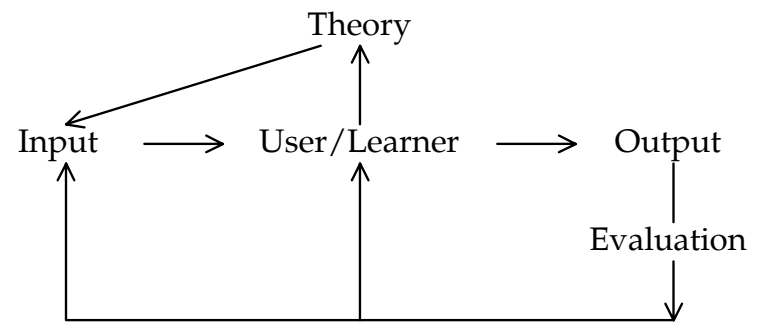

Figure 3: The functional-cognitive approach to dictionary design

(Cf. also Hegelheimer and Chapelle 2000.)

Within the field of SL instructional design, a number of research instruments have been developed to probe online how users process the information provided in documents and what knowledge stores, skills and strategies they employ to this end. These include, inter alia:

- think-aloud protocols (i.e. verbal reports by the user while interacting with the document, which can be followed up by interviews).

- constructive-interaction protocols - a variant of the think-aloud proto$\mathrm{col}$ - in which pairs of users use a document together and report aloud on how they access and use the information in the document to achieve their specified task.

Transcripts of these interactions are used to infer how users reason during processing of input and what hypotheses they generate while interacting with the content of a document.

- tracker technology which is incorporated in CALL applications and which records every action a user makes while interacting with the input material.

These files are used to determine what material in a document is selected by the user for processing, how often it is consulted and what amount of time is spent on it. Correlations are then determined between this information, the user's output performance, and specific design elements of the input document.

These auxiliary research instruments are used to support the more traditional methods of empirical evaluation, such as attribute-interaction testing (AIT research designs), in which the strength of correlational links between specific design elements of a document and the user's output performance is established. (Cf. Hegelheimer and Chapelle 2000 for a discussion of the methodological issues involved.)

However, an analysis of the cognitive processes, strategies and mental representations required for the successful completion of any task is not enough. As indicated in section 3.1, various user, text, task and contextual variables have been shown to mediate the successful execution of the processes and 
representations required for the processing of the information provided in a document. Therefore, in designing a functional document for a specific purpose, the influence of these variables on the successful completion of any task also have to be accounted for in the design of a document.

In line with the assumptions and methodology outlined above, the cognitive-functional approach to document design can be operationalized in the following steps:

(i) Give a model-theoretic account of the linguistic and other kinds of knowledge, cognitive processes, skills and strategies and mental representations that are required for the successful completion of the task for which the user consults a document.

(ii) Determine the mediating user, textual, task and contextual variables that have been shown empirically to mediate the successful use of a document for a specific task.

(iii) Deduce hypotheses from (i) and (ii) with regard to the appropriate design of the input document that would optimize the processing of the required information and design the document accordingly.

(iv) Empirically evaluate the success of the design of the document and determine if and how its success or failure can be attributed to the underlying theory of information processing.

(v) If not successful or only partially successful, devise an alternative design and empirically test its functional quality with regard to the intended users, functions and specific contexts of use.

(Cf. also Chun and Plass 1997.)

Obviously, the cognitive-functional approach to design requires explicit, comprehensive and empirically tested theoretical models of all the mediating cognitive variables that underlie the successful processing of the visual and verbal information provided in documents. Despite the affinity in the field of document design and instructional design for Levelt's processing model (cf. Levelt 1989), we have as yet no single comprehensive model to account for all the variables involved in processing information from all types of texts. What we do have, though, is a number of partial theories, each focussing on at least some of the variables involved.

\subsubsection{Cognitive Variables and Dictionary Design}

Turning now to the field of lexicography, it must be noted that very few researchers, or for that matter lexicographers, have explicitly and/or in a comprehensive fashion linked the design of a dictionary to the cognitive processes and skills required for successful dictionary consultation. Scholfield (cf. Scholfield 1982) was probably one of the first to sensitize lexicographers and researchers to the fact that a set of complex cognitive processes and skills underlie dictionary consultation in any context of use. However, since this seminal article of Scholfield, hardly any theoretical research has been forthcoming that 
probes the cognitive complexities involved in successful dictionary consultation, and very few attempts have been made to systematically and in a theoretically motivated way link the design of a specific dictionary to specific theoretical models. As noted in Swanepoel (2000), the same situation holds with regard to experimental testing of the functional quality of the (re)design features of existing dictionaries.

Given the above state of affairs within the field of lexicography, the cognitive-functional approach with its concomitant set of assumptions, methodologies and techniques could be used as a guideline to redress the current problems with functional dictionary design. In the next section, we outline some of the key issues that will have to be addressed in such an approach and relate it to current approaches and experimental findings in SL instructional design, specifically current research on how to design functional lexicographic support for CALL materials.

\section{Designing Functional Dictionaries}

\subsection{Determining Functional and Cognitive Variables}

In the prototypal case, dictionaries and other word books have the primary function of providing the user with information on the linguistic - often "encyclopaedic" - characteristics of the lexemes of a language, should such a need arise in the course of executing specific tasks (e.g. decoding, encoding, and acquisition tasks).

In line with the cognitive-functional approach, the first step in designing a dictionary would require that the designer should get answers to all, or at least some of the following questions depending on the kind of major task users engage in:

(i) Precisely for what kind of tasks (reading, writing, translating, vocabulary acquisition, etc.) are various kinds of dictionaries used?

(ii) What cognitive processes, skills, strategies and mental representations are involved in the successful execution of such a task?

(iii) What role does lexical knowledge play in the successful execution of the task?

(iv) What constitutes lexical knowledge?

(v) How is lexical knowledge stored and accessed in the mental lexicon?

(vi) What kinds of gaps could arise in the user's lexical knowledge and what implications does that have for the successful execution of the task?

(vii) What strategies - other than consulting a dictionary - do/can users employ to compensate for these lexical deficiencies?

(viii) Under what circumstances will users revert to dictionary consultation to address a gap in their lexical knowledge?

The first set of questions is aimed at elucidating the kinds of lexical needs that could prompt dictionary consultation in specific contexts of use, and, by exten- 
sion, the kind of lexical information that a dictionary of a specific kind should include. However, the set of questions above do not only aim to give a designer an answer as to the kind of lexical information that has to be included in dictionary entries for specific tasks, but also as to how users could contextually (i.e. in terms of the local task involved and their assessment of their specific lexical needs) frame their search questions when reverting to a dictionary for help.

A number of the answers to the first sets of questions the designer needs are (in more or less detail) exactly those that user-research is aimed at providing or, at least, have provided partial answers to: what kinds of users use what kinds of dictionaries for what kinds of activities. Wiegand (1998) provides an overview and a critical assessment of existing studies. Dictionary typologies, including those that focus on mixed categories such as the set of electronic dictionaries (cf. Nesi 2000), are an important supplementary source in answering the questions above.

In most user-studies users are differentiated into broad categories on the basis of their linguistic competence in a language, for example, a distinction is made between first, second and foreign language users, and, with regard to the latter, distinctions are made, for example, between beginners, intermediate and advanced users. These distinctions are more often used as the sole basis on which to predict the kinds of lexical knowledge users will/ought to have and, consequently, what kinds of lexical problems they will/could encounter when engaging in specific tasks. However, there are a number of other mediating variables that the designer has to keep in mind when assessing how the information provided by this first set of questions should be evaluated in terms of the implications they have for the design of a dictionary. Most of these are user variables and task variables. For example, users do not only differ individually from one another in terms of their lexical competence, but also in terms of their ability to perform certain tasks (reading, writing, etc.), their ability to detect and determine their lexical needs in specific communicative situations, and their mastery of compensatory skills when confronted with lexical gaps. Likewise, the kinds of tasks users engage in, may also show great variety in the degree of lexical competency they demand.

There are a number of theoretical models that can guide the dictionary designer in analysing the cognitive processes, strategies, skills, and representations that underlie each of the various kinds of tasks users engage in and the way lexical knowledge features in the execution of those tasks. Given its empirical support, Levelt's model for L1 encoding and decoding (cf. Levelt 1989) and adaptations thereof for explaining L2 encoding and decoding activities, lexical gaps and compensatory strategies feature the most prominently (cf. Swanepoel and Van de Poel (forthcoming) for a discussion).

Of the activities that users engage in, reading and the role that lexical knowledge plays in this process has probably received the most attention. Reading in a L2 is a complex skill (cf. Urquhart and Weir 1998), which requires 
not only adequate lexical knowledge of the L2, but also knowledge of the topic and world knowledge, plus a variety of inferencing and synthesizing skills. Users have a variety of compensatory mechanisms they can revert to when their lexical knowledge fails them, and, depending on their knowledge of the topic and their skills in inferring the meaning of unknown words from context, are able - in different degrees - to make good what they lack in lexical knowledge.

\subsection{Dictionary Consultation}

We now turn to the complexities of the dictionary consultation process itself.

In the field of lexicography, the knowledge, skills and strategies that a user has to master for successful dictionary consultation are usually analysed under the rubric of "dictionary reference skills". Broadly speaking, these can be divided into the following composite knowledge, skills and strategies, each of which has also been shown to be those aspects of dictionary consultation with which users have problems (cf. Bogaards 1998 and Scholfield 1982):

- finding the relevant information in the appropriate dictionary,

- comprehending the information provided,

- evaluating the information provided, and

- applying the acquired knowledge to the task at hand.

Each of these can be further broken down into a number of variables.

Finding the relevant information in the appropriate dictionary requires

- knowledge of the various types of dictionaries available, and specifically

- of the one(s) best suited to provide the necessary information, and

- given the various formats in which electronic dictionaries provide lexical information, also of the best format for the presentation of the information for the search at hand,

- knowledge of how the information is organized in the dictionary, i.e. of the principles underlying its macro- and microstructure and its crossreferencing system, as well as of the contents and structure of the information contained in its appendices,

- the ability to frame the lexical information required in the (most appropriate) search format required by the dictionary, and

- practical skills in using the above knowledge to locate the required information in a specific dictionary.

(Cf. also Scholfield 1982.)

No uniform macro- and microstructural organization has yet been proposed or adopted by the designers of printed dictionaries, and very little research has in fact been done on what would constitute the most effective kind of macrostructural presentation with regard to such variables as 


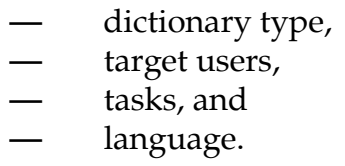

With regard to printed dictionaries, a number of new design features have been incorporated in learner's dictionaries to assist the learner in locating the correct information on the microstructural level, such as ordering the senses of lexemes according to corpus frequency data, the use of so-called "signposts" and/ or advanced organizers. Again, however, the functionality of these features has not been tested empirically, and we have little knowledge of the mediating variables that impinge on their effectivity.

Much of the knowledge and skills referred to above have become redundant in consulting electronic dictionaries. As both Geeraerts (2000) and Nesi (2000) point out, the search facilities provided for in electronic dictionaries eliminate the need for most of this knowledge and skills. Even the ability of formatting appropriate queries is alleviated by the ability of the computer to execute searches (and in various databases) on partially specified strings of a lexeme, if available, by "sound alike" searches, and wildcards. The crucial question, however, is not what is technologically possible, but what users want and need, and this has to be determined empirically.

The first three variables above address the skills and knowledge a user has to possess to locate the information in a dictionary. Once the user has located the required information, interpreting/understanding the information provided in a dictionary article becomes the following hurdle. The complexities faced by both the user and the designer, can be explicated in terms of the following schematic representation:

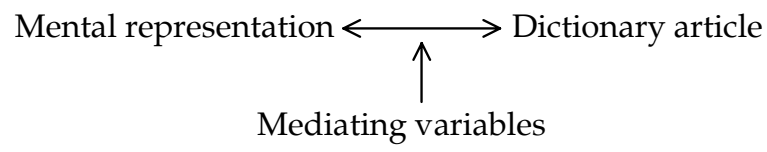

Figure 4: Building a mental representation from dictionary information

To be able to understand (and finally acquire) the information provided in a dictionary on the grammatical features of a lexeme, the user

- has to have a knowledge of the lexicographic principles that underlie the encoding of the lexical information, i.e. the lexicographic codes (symbols, layout and typography) used to identify and differentiate the various information categories (i.e. information on a lexeme's morphology, syntax, semantics, stylistics, usage, etc.),

- must be able to identify which information is encoded explicitly and which only implicitly, and 
- must be able to interpret/understand the information provided (explicitly and implicitly) on the grammatical features of a lexical item, i.e. build a mental representation of the lexical information provided in a dictionary article.

For the dictionary designer the crucial questions are:

- What constitutes the grammatical characteristics of a lexeme, i.e. what information should be included in a dictionary/article?

- What cognitive processes, knowledge, representations, skills and strategies do users employ in trying to understand (and finally to acquire) the grammatical features of a lexical item, i.e. to build a mental representation of the information provided?

- What kind of presentation (encoding) and layout of the grammatical characteristics of a lexeme in a dictionary article will optimize the construction of a mental representation of these characteristics?

- What mediating (user, task, text) variables have been shown experimentally to influence this process?

\subsubsection{Theoretical Models}

With regard to the first question, dictionary designers have relied for the most part on what linguistics has to offer with regard to the characterization of "lexical knowledge". Laufer and Paribakht (1998: 366-367) note, however, that there is no clear and unequivocal consensus as to what exactly constitutes lexical knowledge. Most researchers accept, though, that lexical knowledge is not an all-or-nothing phenomenon, but a continuum consisting of several layers and dimensions of knowledge, skills and strategies that develop over time. Most researchers accept, furthermore, that acquiring a lexical item involves acquiring a mental representation of all its grammatical characteristics (broadly defined). These include its orthographic, phonemic, morphologic, syntactic (including its collocational properties) and semantic and stylistic/use characteristics. Lexical semantic knowledge includes not only the lexical item's intraconceptual characteristics (primary and secondary senses, polysemic structure, etc) but also its interconceptual structure, its relation to other knowledge structures (frames and schemata) and its reference. Lexical comprehension does not only involve an understanding of the semantics (intra- and interconceptual structure) of a lexical item, but also of how its semantics interacts with its syntactic and morphologic properties, and inter alia, with all other knowledge structures mentioned above. In short, as proposed in most lexical semantic theories, it is accepted that the mental representations of lexical items form intricate and multidimensional networks in the mental lexicon of the learner (cf. Aitchinson 1994, Geeraerts 1989 and Schmitt 1997).

Although this whole range of information categories may constitute the knowledge users have of lexical items, no dictionary includes all of these for 
every lexical item. In choosing what information to include in a dictionary, designers are guided by a number of pragmatic and functional considerations, viz. the type of dictionary and the lexemes chosen for lexicographic treatment, the information needs of the end-user and the constraints imposed by the limitations of space and the linearity of the printed dictionary (cf. Geeraerts 1989).

With regard to the presentation (encoding and layout) of the lexical information provided in dictionary entries, very few dictionary designers have explicitly linked their dictionary design to models of the knowledge, processes and strategies underlying the understanding and acquisition of the grammatical information of a lexeme. In the field of SL instructional design, however, a number of researchers have reverted in this regard to Levelt's model of the lexicon and to adaptations of it to account for SL lexical knowledge acquisition and use (cf. De Bot, Paribakht and Wesche 1997, and Dörnyei and Kormos 1998).

According to Levelt's model, the mental representation of a lexical item is organized into three distinct representational levels: the conceptual level, the lemma level and the lexeme level (morphonologic word form). The lemma specifies the semantic/conceptual features (propositional content and structure) and syntactic-semantic features (syntactic category, argument structure, grammatical functions of arguments, complementation structure and diacritic parameters). De Bot, Paribakht and Wesche (1997: 313) give the following example of a verb lemma in which the semantic and syntactic information and their interaction (mapping) are explicated:

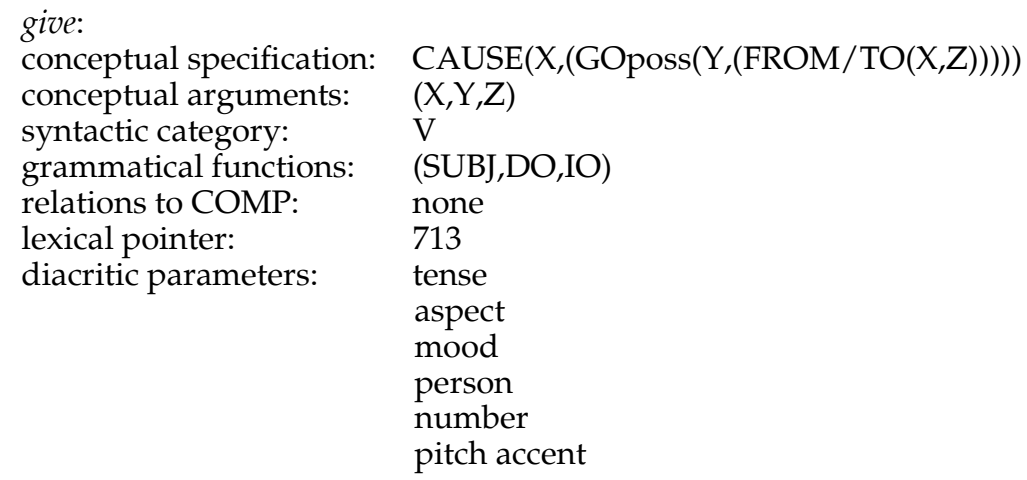

In terms of this model, building up a mental representation of the grammatical features of a lexeme is a process of construction in which the learner uses available linguistic input to infer the grammatical features of a lexical item to fill in the slots at the various representational levels of a lexical template and to establish links between the various levels. A learner will have acquired a lexical item only when he/she has acquired all the relevant grammatical features as specified at the various levels, has established links between the various levels, and - as is assumed in some definitions of lexical knowledge - is also able to activate the required lexical knowledge in decoding and encoding tasks. A 
learner's knowledge of a lexical item could, however, also be only of a partial nature, i.e. include any one or more but not all of the lexical characteristics specified at the different levels of representation and be the result of the fact that characteristics at the various levels of presentation are not linked.

Although this model provides a theoretical basis for understanding what the content and structure of the mental representations of lexical items could be like, it obviously is also rather vague on a number of aspects. The first is the fact that it does not explicate what knowledge, processes, strategies and skills underlie the comprehension process, i.e. how a user would interpret, extract and synthesize the lexical information provided in a dictionary entry for give in the form of the mental representation. Nor does Levelt's model indicate what variables could have an impact on the comprehension process itself, such as the knowledge the user has to have of the lexicographic conventions used to encode grammatical information in various kinds of dictionaries.

Secondly, the model is underspecified with regard to all the information categories that are taken to constitute lexical knowledge (cf. the discussion above). For example, it does not provide for stylistic and pragmatic information and it is not clear how the model provides for the multidimensional structure of lexical meaning. With regard to the latter, Geeraerts (1989) indicates that most polysemic lexical items do not have a set of clearly delineated senses (as is often provided in dictionary entries) but - as is the case with prototype categories - a number of mostly overlapping senses that relate to each other in a variety of ways. The challenge for the dictionary designer, of course, is to come up with a representation format/formats that would reflect the complexities of the internal structure of the semantics of a lexeme and thereby to optimize the comprehension process.

Optimizing the encoding of information on the meaning of lexemes has certainly received the most attention, especially in SL lexicography, as it has also proven to be the most problematic. Besides the lexicographic definitions of various kinds, the other major tools lexicographers use for this purpose are verbal examples and illustrations. The user has the task of building up a mental representation of the meaning of a lexeme from the information provided by these descriptive devices, separately and in conjunction with each other. This can be schematically depicted as follows:

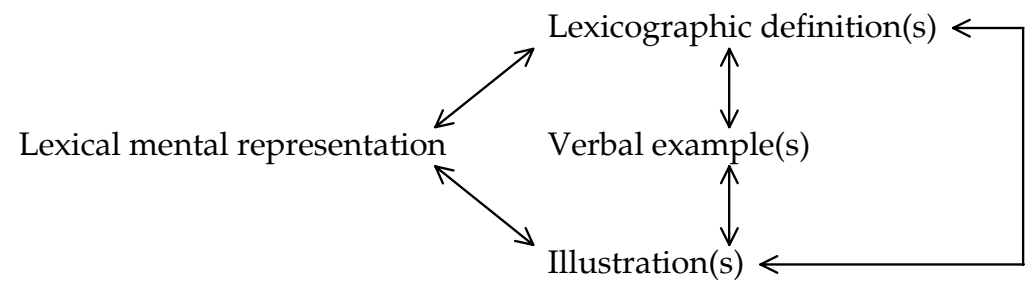

Figure 5: Building-up a mental representation of lexical meaning

Again, such a schematic depiction merely captures the information sources that the user can utilise in building up the mental representation of the meaning of 
a lexeme, but not the complexities of the knowledge and cognitive processes involved in inferencing/extracting and synthesizing the information from these three sources to construct a mental representation of the meaning of a lexeme.

With regard to the latter, one could assume that, although unspecified, learners/users employ the same cognitive resources, strategies and skills as those that they employ when learning from any other contexts of language use. But lexicographers need more detailed information on

- how and what semantic information users extract, process and store and finally integrate from definitions, verbal examples and illustrations, and

- how this information is finally organized in the mental lexicon of the user.

Most theories are rather vague with regard to these two aspects and theoretical research to elucidate these aspects are crucially needed. Despite this, a number of new design features have been incorporated into dictionaries, especially learner's dictionaries, based on (although often not explicitly stated) assumptions of the knowledge, processes, strategies and skills involved in building up a mental representation of the meaning of a lexeme from definitions and verbal examples, and of the variables that effect this process.

\subsubsection{Design Innovations in Lexicography}

The assumption that the user first has to understand the lexicographic definition to be able to construct a representation of a lexeme's meaning, motivates the use of a controlled/limited defining vocabulary in definitions and the elimination of all kinds of dictionarese (symbols, labels, some abbreviations, parentheses, etc.) and arcane expressions in definitions. With regard to the former, the assumption is that elimination of dictionarese takes the burden off the user of first having to translate the meaning of these symbols, labels, etc. and of determining how their meanings relate to that provided by the rest of a definition. Likewise, restricting the defining vocabulary goes a long way to ensuring that the user will have a command of the lexical items that are used to define the meaning of a lexeme. As some dictionary critics have pointed out though, a limited defining vocabulary also has a number of drawbacks, especially that it often leads to vague definitions, which thwarts the goal of comprehensibility.

As indicated in section 1, the so-called full-sentence definition format has become a standard feature of most learner's dictionaries. Besides incorporating information on the syntactic features of the defined lexical item, its use is motivated by the assumption that it has the format of folk definitions, and would therefore be easier to comprehend. However, the superiority of this definition format still has be supported experimentally (cf. Cumming, Crop and Sussex, 1994). Furthermore, the full-sentence definition and phrasal definitions are only two of the various kinds of lexicographic definition formats. In line with the functional-cognitive methodology, one would expect that the design of diction- 
ary definitions should be guided by explicit models of the acquisition and mental storage of lexical meaning and by research on the variables that mediate their effectivity for different kinds of users.

With regard to the use of verbal examples, Harras (1989), following Wiegand, explicitly states that we are in need of a lexicographic theory of the use of verbal examples. Such a theory would have to explicate

- how verbal examples support lexicographic definitions by clearly indicating what relationship(s) exist between examples and other elements of a dictionary article (including the definition), and

- what makes a good lexicographic example.

The second normative component of the theory would no doubt be linked to the first component in that good examples would be those that either illustrate the use-aspects of the other elements of a dictionary article, add to the information these other elements already convey (cf. Harras 1989 for further discussion), or independently contribute information to the mental representation of a lexeme (as spelt out in the lexical model of Levelt above). Again, however, whatever norms may be deduced for "good" examples, these norms still have to be tested empirically, and the mediating variables that impinge on the effectiveness of examples with regard to the three aspects mentioned above, have to be determined.

Levelt's model does not provide in an explicit way for the use of illustrations as a means for explaining the meaning of lexemes. Given the fact that illustrations are widely used in printed dictionaries (cf. Hupka 1989) and that electronic dictionaries provide for multimedia input (illustrations, graphics, animation, video) an adequate theoretical model for designing adequate dictionaries should also account for the processing of visual information.

To this end a number of researchers in the field of SL instructional design revert to Paivio's dual coding theory (cf. Plass 1998, Chun and Plass 1997, and Plass, Chun, Mayer and Leutner 1998 for a discussion). According to this theory (Paivio 1986) the information presented in verbal and visual form are processed differently and stored in two different systems in the cognitive component. Verbal input represents information in the symbolic structures of a language and it is processed sequentially to form, first of all, propositional mental representations of the meaning of the linguistic input. The propositional representations are then mapped onto a mental model of the information that is presented.

Visual input, on the other hand, conveys information by means of visuospatial structure (i.e. spatial arrangements of the components of an image) and the information is encoded in parallel or simultaneous fashion. The comprehension of an image requires establishing an analogy between the picture and a corresponding mental model. Image comprehension thus bypasses the propositional representation of information and is, therefore, assumed to be 
language independent (cf. Chun and Plass 1997).

When represented with verbal input and visual input that relates to the verbal input, the learner has to make referential connections between the two mental representations that are established by the interpretation process. In the case of the acquisition of unknown words, this implies that the learner will have to match his/her mental representation of the semantic/conceptual features of a lexical item with the features and their relations to each other in the mental model of the visual input.

It is now generally accepted that the comprehension of the meaning of lexemes can be greatly enhanced by supporting lexicographic definitions with illustrations, especially where very complex concepts have to be defined. As in the case of lexicographic examples, however, we are still in need of

- theoretically motivated analyses of how the information provided in illustrations relate to and are linked to the information provided in lexicographic definitions, and

- experimental evidence on what constitutes a good lexicographic illustration (for what aspects of the meaning of lexemes and for what word classes).

(Cf., e.g., Chun and Plass 1997, Hupka 1989, Mayer 1999 and Schriver 1997.)

With regard to the latter, Chun and Plass (1997) indicate that a number of variables have been shown empirically to either enhance or impede the mediating effect of visual input in building up a mental representation of the meaning of a lexeme. The most important of these are the kind of visual material used, the integration of visual and verbal materials, and the cognitive learning styles of users (visualizers vs. verbalisers).

\subsection{Applying Acquired Lexical Knowledge}

The last aspect of dictionary consultation that will receive attention, is the ability of the user to apply the lexical knowledge that has been acquired from the dictionary to the task that prompted the consultation process in the first place. In this respect, the information provided by dictionaries on the meaning of lexemes again illustrates the problems users can experience. Dictionary consultations are often triggered by highly context specific meanings of lexical items, while dictionaries in most cases only provide for the most general, prototypal meanings of lexemes. The user, therefore, has to be able to contextualize the more general meaning to the specific meaning required by the context of use of a lexeme - a skill that SL learners, for example, often lack.

Scholfield (1981) proposes the use of contextual paraphrases as dictionary definitions to help the user overcome this problem. Another, and very old design solution to this problem is to annotate/gloss difficult/unknown words in texts intended for the SL learner. Text glosses provide users with only the 
relevant contextual meaning of an unknown lexical item. Glosses thus relieve students from the arduous task of finding the relevant senses of unknown words in printed dictionaries, and, if given as a contextual paraphrase of an unknown word, of having to integrate some generic meaning from a dictionary in the word's context of use. In electronic texts the type of glosses are furthermore expanded to include a variety of information types (e.g. translations, definitions in the L1 and the L2, encyclopaedic information, visual glosses (graphics, pictures, animation and video) and sound), thereby providing for the different learning styles of different dictionary users. The layout and design possibilities of computer screens also allow for the fact that glosses can be presented and integrated into textual (multimedia) input in such a way that they do not negatively impact on the comprehension process. Glossing has proven to be rather beneficial, both in the case of printed texts and electronic texts, and a growing body of research has been devoted to this topic (cf. Chun and Plass 1997, Lomicka 1998, Roby 1999, and Yeung, Putai and Sweller 1997).

In such cases, however, the printed dictionary functions merely as a lexical resource for the teacher/materials designer who has to select the relevant senses, translations, appropriate visual materials, etc. from existing dictionaries, and come up with a contextually relevant presentation of the information in glosses that can support the learner. Research on how such glosses can be automatically generated in CALL applications incorporating fully fledged electronic dictionaries is still in its infancy. Furthermore, a number of deleterious effects have been shown to influence the functional quality of multimedia glosses (cf. Chun and Plass 1997 and the references cited above).

No doubt, other possibilities than contextual paraphrases and glosses could be devised, but again the question of which one of these is the most effective for what kinds of users for what kinds of tasks, is an empirical one.

\section{Conclusion}

In section 1 of this article, I argue that, despite the commitment to improving the functional quality of dictionaries, two major methodological problems currently trouble practical lexicography and metalexicographic research, viz. that

- the evaluation of the functional quality of dictionaries does not feature prominently in either the dictionary design process, or in current metalexicographic research, and

- when it does feature, it is most often based on impressionistic and anecdotal evidence or commonsense heuristics, not on the application of generally accepted scientific methodologies and techniques, such as theoretically driven experimental research.

Subsequently, an outline is given of the methodology used in the fields of web design, document design and instructional design to tackle the functional qual- 
ity problem. As I have indicated throughout, this methodology also provides a conceptually coherent framework for the design of dictionaries, either in printed or electronic format, and for assessing the functional quality of their design features. Secondly, the framework provided by the cognitive-functional approach to design not only explicates how current research in lexicography conceptually relates to dictionary design, but also what areas are in dire need of further theoretical elaboration and experimental research.

No doubt, not all the relevant variables that optimize the functional quality of dictionaries have been identified and explicated in this article. That would be part of an ongoing research programme within the field of lexicography - a programme in which the traditional fields of lexicographic research is also supplemented by a concern with functional quality.

If lexicographers are really concerned about user needs and have the real goal of improving the functional quality of dictionaries, they simply have to take the methodological leap that is required of them. The methodology outlined in this article is precisely aimed at achieving this. It provides for the design of theoretically and empirically motivated dictionaries, but then in a way that cognisance is taken of what has already been done in the field of lexicography on the functional quality of dictionaries and what areas are in need of further research.

\section{References}

\section{A. Dictionaries}

OALD5: Crowther, J. (Ed.). 1995. Oxford Advanced Learner's Dictionary of Current English. Oxford: Oxford University Press.

CIDE: Procter, P. (Ed.). 1995. Cambridge International Dictionary of English. Cambridge: Cambridge University Press.

COBUILD2: Sinclair, J. (Ed.). 1995. Collins COBUILD English Language Dictionary. London: HarperCollins.

LDOCE3: Summers, D. (Ed.). 1995. Longman Dictionary of Contemporary English. Harlow: Longman.

\section{B. Other Sources}

Aitchinson, J. 19942. Words in the Mind: An Introduction to the Mental Lexicon. Oxford: Blackwell.

Boogaards, P. 1998. Scanning Long Entries in Learner's Dictionaries. Fontenelle, T. et al. (Eds.). 1998: 555-562.

Chun, D.M. and J.L. Plass. 1997. Research on Text Comprehension in Multimedia Environments. Language Learning and Technology 1: 60-81.

Cumming, G., S. Crop and R. Sussex. 1994. On-line Lexical Resources for Language Learners: Assessment of Some Approaches to Word Definition. System 23: 369-377. 
De Bot, K., T.S. Paribakht and M. Bingham Wesche. 1997. Toward a Lexical Processing Model for the Study of Second Language Vocabulary Acquisition: Evidence from ESL Reading. Studies in Second Language Acquisition 19: 309-329.

De Jong, M. and T. van der Geest. 2000. Characterizing Web Heuristics. Technical Communication 47: 3001-322.

De Schryver, G.-M. and D.J. Prinsloo. 2000. Dictionary-Making Process with 'Simultaneous Feedback' from the Target Users to the Compilers. Heid, U., S. Evert, E. Lehmann and C. Rohrer (Eds.). 2000: 197-210.

Dörnyei, Z. and J. Kormos. 1998. Problem-Solving Mechanisms in L2 Communication: A Psychological Perspective. Studies in Second Language Acquisition 20: 349-385.

Fontenelle, T. et al. (Eds.). 1998. EURALEX'98 Proceedings. Liège: University of Liège Press.

Gaffney, G. 2000. Gerry Gaffney's 'Introduction to Web Usability'. Online: http://www.infodesign.com.au Retrieved: 2000-08-28.

Geeraerts, D. 1989. Wat er in een woord zit. Facetten van de lexicale semantiek. Leuven: Peters.

Geeraerts, D. 2000. Adding Electronic Value. The Electronic Version of the Grote van Dale. Heid, U., S. Evert, E. Lehmann and C. Rohrer (Eds.). 2000: 75-84.

Groot, P.J.M. 2000. Computer Assisted Second Language Vocabulary Acquisition. Language Learning and Technology 4: 60-81.

Harras, G. 1989. Zu einer Theorie des lexicographischen Beispiels. Hausmann F.J., O. Reichmann, H.E. Wiegand and L. Zgusta (Eds.). 1989: 607-613.

Hausmann, F.J., O. Reichmann, H.E. Wiegand and L. Zgusta (Eds.). 1989. Wörterbücher. Ein internationales Handbuch zur Lexikographie. / Dictionaries. An International Encyclopedia of Lexicography. / Dictionnaires. Encyclopédie internationale de lexicographie. Berlin/New York: Walter de Gruyter.

Hegelheimer, V. and Carol A. Chapelle. 2000. Methodological Issues in Research on Learner-Computer Interactions in CALL. Language Learning and Technology 4: 41-59.

Heid, U., S. Evert, E. Lehmann and C. Rohrer (Eds.). 2000. Proceedings of the Ninth EURALEX International Congress, EURALEX 2000. Stuttgart: Institut für Maschinelle Sprachverarbeitung, Universität Stuttgart.

Herbst, T. 1999. On the Way to the Perfect Learner's Dictionary: A First Comparison of OALD5, LDOCE3, COBUILD2 and CIDE. International Journal of Lexicography 12: 321-355.

Hoeken, H. 1995. The Design of Persuasive Texts: Effects of Content, Structure, and Style on Attitude Formation. Unpublished Ph.D. thesis. Tilburg: Catholic University of Brabant.

Hupka, W. 1989. Die Bebilderung und sonstige Formen der Veranschaulichung im allgemeinen einsprachigen Wörterbuch. Hausmann F.J., O. Reichmann, H.E. Wiegand and L. Zgusta (Eds.). 1989: 704-726.

Køhler Simonsen, H. 2000. Design, Development and Compilation of a Bilingual Multifunctional Intranet-based Differential Telecome Lexinome at a Major Danish Telecoms Group. Heid, U., S. Evert, E. Lehmann and C. Rohrer (Eds.). 2000: 89-96.

Laufer, B. 2000. Electronic Dictionaries and Incidental Vocabulary Acquisition: Does Technology Make a Difference? Heid, U., S. Evert, E. Lehmann and C. Rohrer (Eds.). 2000: 849-854.

Laufer, B. and T.S. Paribakht. 1998. The Relationship between Passive and Active Vocabularies: Effects of Language Learning Context. Language Learning 48: 365-391.

Levelt, W.J.M. 1989. Speaking: From Intention to Articulation. Cambridge, MA.: MIT Press. 
Levelt, W.J.M. 1994. Onder woorden brengen: Beschouwingen over het spreekproces. Haarlem: Hollandsche Maatschappij der Wetenschappen.

Lomicka, L.L. 1998. "To Gloss or Not to Gloss": An Investigation of Reading Comprehension Online. Language Learning and Technology 1: 41-50.

Mayer, R. 1999. Research-based Principles for the Design of Instructional Messages: The Case Of Multimedia Explanations. Document Design 1: 7-19.

Multimedia Services. 2000. Computer-based Training. ADDIE Model. Online: http://www.orci. com/ vanzant/cbt.html Retrieved: 2000-02-10.

Müller-Landmann, S. 2000. Design eines Internet-Lexicons zwischen Recherche und Rezeption. Heid, U., S. Evert, E. Lehmann and C. Rohrer (Eds.). 2000: 97-106.

Nesi, H. 2000. Electronic Dictionaries in Second Language Vocabulary Comprehension and Acquisition: The State of the Art. Heid, U., S. Evert, E. Lehmann and C. Rohrer (Eds.). 2000: 839848.

Nielsen, J. 1994. Heuristic Evaluation. Nielsen, J. and Mack (Eds.). 1994: 25-62.

Nielsen, J. 1999. Useit.com: Jacob Nielsen's Website. Online: http: //www.useit.com Retrieved: 200009-28.

Nielsen, J. and R.L. Mack (Eds.). 1994. Usability Inspection Methods. New York: John Wiley and Sons.

Paivio, A. 1986. Mental Representations. A Dual Coding Approach. Oxford: Oxford University Press.

Plass, Jan L. 1998. Design and Evaluation of the User Interface of Foreign Language Multimedia Software: A Cognitive Approach. Language Learning and Technology 2: 35-45.

Plass, J.L., D.M. Chun, R.E. Mayer and D. Leutner. 1998. Supporting Visual and Verbal Learning Preferences in a Second-Language Multimedia Learning Environment. Journal of Educational Psychology 90: 25-36.

Roby, W.B. 1999. "What's in a Gloss?" Language Learning and Technology 2: 94-101.

Rundell, M. 1999. Dictionary Use in Production. International Journal of Lexicography 12: 35-54.

Sato, H. 2000. Multi-Functional Software for Electronic Dictionaries. Heid, U., S. Evert, E. Lehmann and C. Rohrer (Eds.). 2000: 863-870.

Schellens, P.J. and M.F. Steehouder. 1994. Tekstontwerp: Schrijven als ontwerpproces. Tijdschrift voor Taalbeheersing 16: 161-172.

Schmitt, N. 1997. Vocabulary Learning Strategies. Schmitt, N. and M. McCarthy (Eds.). 1997: 199227.

Schmitt, N. and M. McCarthy (Eds.). 1997. Vocabulary; Description, Acquisition and Pedagogy. Cambridge: Cambridge University Press.

Scholfield, P. 1981. Vocabulary Explanation by Paraphrase in Context. Studia Anglica Posnaniensia 15: 103-121.

Scholfield, P. 1982. Using the English Dictionary for Comprehension. TESOL Quarterly 16: 185-194.

Scholfield, P. 1999. Dictionary Use in Reception. International Journal of Lexicography 12: 13-34.

Schriver, K.A. 1989. Evaluating Text Quality: The Continuum from Text-focused to Reader-focused Methods. IEEE Transactions in Professional Communication 32: 238-255.

Schriver, Karen. 1993. Quality in Document Design: Issues and Controversies. Technical Communication 40: 239-257.

Schriver, Karen. 1997. Dynamics in Document Design. New York: John Wiley. 
Shelby, A.N. 1994. Communication Quality as Metacommunication: A Conceptual Analysis. Van Waes, L., E. Woudstra and D. van den Hoven (Eds.). 1994: 5-17.

Sims-Knight, J.E. 1992. To Picture or Not to Picture: How to Decide. Visible Language 29: 325-388.

Swanepoel, P. 2000. Providing Lexicographic Support for Sl Vocabulary Acquisition: What Kind, under What Conditions, for Whom, and Why? Heid, U., S. Evert, E. Lehmann and C. Rohrer (Eds.). 2000: 403-419.

Swanepoel, P. and K. van de Poel. Forthcoming. Designing Effective Lexical Support for SecondLanguage Acquisition in Computer-Assisted Language Learning: The LINC Approach.

Tono, Y. 2000. On the Effects of Different Types of Electronic Dictionary Interfaces on L2 Learners' Reference Behaviour in Productive/Receptive Tasks. Heid, U., S. Evert, E. Lehmann and C. Rohrer (Eds.). 2000: 855-862.

Urquhart, S. and C. Weir. 1998. Reading in a Second Language: Process, Product and Practice. London: Longman.

Van der Geest, T. and J.H. Spyridakis. 2000. Developing Heuristics for Web Communication. Technical Communication 47: 301-311.

Van Waes, L., E. Woudstra and P. van den Hoven (Eds.). 1994. Functional Communication Quality. Amsterdam: Rodopi.

Wiegand, H.E. 1998. Wörterbuchforschung. Untersuchungen zur Wörterbuchbenutzung, zur Theorie, Geschichte, Kritik und Automatisierung der Lexikographie. Berlin: Walter de Gruyter.

Wilson, B., D. Jonassen and P. Cole. 1993. Cognitive Approaches to Instructional Design. Online: http://wwww.cudenver.edu/ bwilson/training.html Retrieved: 2000-02-17.

Yeung, A.S., J. Putai and J. Sweller. 1997. Cognitive Load and Learner Expertise: Split-attention and Redundancy Effects in Reading with Explanatory Notes. Contemporary Educational Psychology 23: 1-21. 